\title{
EL PRINCIPIO DE INCLUSIÓN DE LA PRUEBA RELEVANTE EN EL CÓDIGO PROCESAL PENAL CHILENO
}

\section{THE PRINCIPLE OF INCLUSION OF RELEVANT EVIDENCE IN CHILEAN CRIMINAL PROCEDURE LAW}

\author{
Juan Sebastián Vera SÁncheZ
}

\begin{abstract}
RESUMEN: En este trabajo desarrollaré argumentos para sostener que el CPP, en sede de admisibilidad, adopta el principio de inclusión de la prueba relevante como criterio general de depuración epistémica. Los argumentos que daré se basarán en consideraciones epistémicas, normativas y extraepistémicas.
\end{abstract}

Palabras clave: Prueba, admisibilidad, criterio de relevancia.

ABSTRACT: In this essay I will develop arguments to hold that in the Chilean criminal procedure law, the principle of inclusion of relevant evidence is adopted as an epistemic criterion of depuration. The arguments that I will provide will be based on epistemic, normative and extra epistemic considerations.

Keywords: Evidence, admissibility, criteria of relevance.

\section{INTRODUCCIÓN}

Es relativamente pacífico asumir que las reglas de exclusión, aplicables en sede de admisibilidad, pueden basarse en fundamentos epistémicos o extraepistémicos ${ }^{1}$, si se busca con ello cautelar la búsqueda de la verdad de lo sucedido o resguardar otros valores o intereses importantes para el sistema normativo, respectivamente.

Damaška denomina a las primeras reglas de exclusión intrínsecas; a las segundas, reglas de exclusión extrínsecas ${ }^{2}$. Este trabajo versará principalmente respecto de las primeras con el objetivo de preguntarse si las normas del CPP recogen un principio general epistémico en la materia.

En efecto, aceptar que hay reglas de exclusión presupone lógicamente, y desde el punto de vista conceptual, que hay una regla de inclusión que pueda ser identificada, respecto de la cual se haga necesaria precisar su sentido y alcance. Ello, con la finalidad de de-

\footnotetext{
Doctor en Derecho Universidad de Barcelona. Profesor Asistente de Derecho procesal, Universidad de Chile. Dirección postal: Av. Santa María 076, Providencia, Chile. Correo electrónico: jsvera@derecho.uchile.cl. Este artículo fue escrito en el contexto de la ejecución del Proyecto FONDECYT de Iniciación No 11180563: "Las condenas fundadas en el testimonio de la víctima en materia penal: ¿epistémicamente posible? ¿jurídicamente aceptable?".

Abreviaturas: Código Procesal Penal chileno= CPP; Corte Suprema de Chile $=$ CS; Constitución Política de la República de Chile = CPR; Federal Rules of Evidence= FRE; Juez de Garantías= JG; Strafprozeßordnung= StPO; Tribunal de Juicio Oral en lo penal= TJOP.

1 Por ejemplo, Ferrer (2007) pp. 42 y s; TARuffo (2008) p. 37; TARuffo (2010) p. 167; Hernández (2010) p. 26.

2 DamašKa (2015) pp. 30 ss. En igual sentido respecto de los intereses en juego, STEIN (2013) p. 249.
} 
finir adecuadamente la función de control que al respecto le compete al juez que conoce de la fase intermedia en nuestro proceso penal.

La distinción entre fundamentos epistémicos y extraepistémicos de las reglas de exclusión no nos puede llevar a pensar equivocadamente que ambas perspectivas están completamente diferenciadas, por un lado, y que la racionalidad probatoria, en este punto, incentiva un análisis puramente epistémico del sentido y alcance de estas reglas, por otro. Las distintas reglas probatorias contenidas en nuestro CPP también pueden ser vistas como un sistema, a partir de cual el legislador configura una serie de opciones políticas entre los diversos intereses en juego. Lo anterior incluso cuando con ello se intenta zanjar cuestiones epistemológicas ${ }^{3}$. En este sentido, el legislador a través de las reglas probatorias busca equilibrar el potencial demostrativo de las pruebas con otros muchos factores ${ }^{4}$. Ello, quizá, ha contribuido a que en el ámbito anglosajón se comparen las reglas de prueba con el "gato Cheshire", el "queso Gruyère"s o con "barcos navegando de forma desintegrada en el mar de la prueba libre" ${ }^{\text {, }}$ porque muchas veces parecen un laberinto de normas desconectadas, llenas de excepciones y contraexcepciones ${ }^{7}$. Lo anterior, especialmente considerando las complejas tensiones entre diversos intereses concurrentes en dicha sede probatoria.

La cuestión aumenta en complejidad de forma exponencial cuando se reconoce que, por ejemplo, muchas de las reglas de prueba del CPP combinan elementos de diversas culturas jurídicas. De hecho, la intensa selección preliminar de las pruebas - de la que da cuenta, en parte, la fase de admisibilidad y la aplicación de las reglas de exclusión en el CPP- ha sido señalado por algunos como un rasgo sobresaliente del modo angloamericano de investigar los hechos ${ }^{8}$. De igual forma se ha reconocido que la libertad probatoria ha tenido más impacto en los enjuiciamientos del civil law ${ }^{9}$. Esta confluencia e interacción de tradiciones también ha de tenerse en cuenta.

En la primera parte de este trabajo me referiré a los criterios empleados en el derecho probatorio para excluir prueba por razones epistémicas. En la segunda parte, abordaré una serie de consideraciones que permiten reconstruir un adecuado contexto institucional de la aplicación de las reglas de exclusión epistémicas en nuestro sistema de enjuiciamiento penal. En la tercera parte, basado en todo lo anterior, desarrollaré el que considero el criterio de inclusión o principio epistémico general que ha recogido nuestro CPP en las normas que regulan la fase intermedia.

3 Ferrer (2007) p. 44; Twining (1997) p. 457.

4 DAMAŠKa (2015) p. 27.

5 Véase, Twining (2006) pp. 211 ss; Jackson (1996) p. 324; Stein (2013) p. 246.

6 Stein (2005) p. 110.

7 DAMAŠKa (2015) p. 27.

8 DAMAŠKa (2015) p. 27.

9 DAMAŠKa (1995) pp. 343 ss. 


\section{CRITERIOS GENERALES DE DEPURACIÓN PROBATORIA POR RAZONES EPISTÉMICAS EN SEDE DE ADMISIBILIDAD}

En el ámbito del "evidence" anglosajón se ha recurrido principalmente al concepto de relevancia como criterio general de depuración epistémica de la prueba en sede de admisibilidad. En el ámbito continental, la misma labor se ha llevado a cabo a través de los conceptos de pertinencia, utilidad e idoneidad. De otro lado, también es posible identificar en la doctrina iberoamericana posiciones sincréticas de ambas tradiciones.

\section{EL CRITERIO DE LA RELEVANCIA}

El concepto de relevancia como criterio que permita depurar la prueba, presenta un carácter indeterminado ${ }^{10}$, y se le ha retratado como una de las más problemáticas cuestiones en relación con el evidence anglosajón ${ }^{11}$, con un pasado bastante confuso ${ }^{12}$. No obstante ello, igualmente es posible identificar algunas nociones o tendencias basales que se asocian a su empleo.

Un elemento importante de la relevancia es su fuerte carácter lógico, a partir del cual la prueba que se admite debe presentar un carácter relacional con los hechos del litigio, de forma que pueda basarse en ella una conclusión acerca de la verdad de los hechos ${ }^{13}$. De igual forma, es posible identificar en la relevancia una noción utilitarista instrumental, pues serán medios de prueba relevantes aquellos que permitan entregar una base cognitiva mínima que posibilite establecer una probabilidad superior a cero respecto de los hechos debatidos ${ }^{14}$. Es decir, la prueba será relevante si su información puede hacer más o menos probable la existencia de cualquier hecho de importancia para el caso ${ }^{15}$. En otras palabras, la prueba es relevante si aporta apoyo o refutación respecto de alguna de las hipótesis fácticas del caso a la luz de los principios generales de la lógica y de la ciencia ${ }^{16}$, especialmente considerando el "stock" social de conocimiento disponible ${ }^{17}$.

El Model Code of Evidence en su Regla 1 define prueba relevante como aquella que tiene alguna tendencia en razón de probar cualquier asunto material incluyendo opiniones ("opinion evidence") y testimonios de oídas ("hearsay evidence") ${ }^{18}$. La regla 401 de las FRE señala que es prueba relevante si: a) si tiene alguna tendencia para hacer los hechos más o

\footnotetext{
${ }^{10}$ MAY (1999), p. 8.

11 TWINING (2006) p.121

12 Burgess-Jackson (1986) p. 465.

13 Taruffo (2008) p. 38; Ingram (2012) p. 46; Nemeth (2001) p. 6; Twining (2006) p.121; Burgess-JackSON (1986) p. 465.

14 TARUfFo (2008) p. 38.

15 MaY (1999) p. 8.

16 Ferrer (2007) p. 42.

17 TWINING (2006) p.122

18 Nemeth (2001) p. 6.
} 
menos probables de lo que sería sin la prueba, y b) el hecho es de importancia para la determinación de la acción ${ }^{19}$.

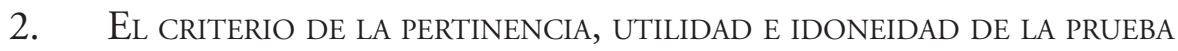

Por su parte, la función de depuración epistémica en un estadio preliminar de juicio, en el ámbito de los procedimientos penales de herencia románica continental, se ha llevado a cabo a partir del empleo de las nociones de pertinencia, utilidad e idoneidad de la prueba. Así, se ha afirmado que la prueba es pertinente cuando exhiba una relación con el thema probandum, es decir, cuando se vincule con el objeto del proceso $^{20}$. La importancia de ello es que el CPP expresamente señala que se debe excluir la prueba "manifiestamente impertinente" (art. 276 inciso $1^{\circ}$ ). Por su parte, se habla de inutilidad de la prueba cuando esta es inadecuada respecto del fin que persigue o cuando es superflua ${ }^{21}$. Lo primero se daría cuando el medio de prueba no es adecuado para verificar con él las afirmaciones de los hechos que se discuten; lo segundo, cuando el medio de prueba es sobreabundante o dilatorio, porque contiene una información a la que se ha accedido o se puede acceder por otros medios de prueba. Por ejemplo, El artículo 283.2 de la Ley 1/2000, 7 de enero "Ley de Enjuiciamiento civil española", señala expresamente que "tampoco deben admitirse, por inútiles, aquellas pruebas que, según reglas y criterios razonables y seguros, en ningún caso puedan contribuir a esclarecer los hechos controvertidos". En este sentido, la importancia del criterio de la utilidad vendría dado por su utilización, de parte de la doctrina y jurisprudencia, en un sentido sinonímico respecto del concepto pertinencia ${ }^{22}$.

En lo que refiere a la inutilidad, este es uno de los criterios por los cuales se habilita en el proceso penal alemán la exclusión de prueba (\$244, III StPO). El medio de prueba es inútil cuando es completamente inidóneo o inasequible para los fines que persigue. Para parte de la doctrina alemana, por ejemplo, la completa inidoneidad podría vincularse con la apreciación de la credibilidad de los testigos ${ }^{23}$. En lo que refiere a la prueba pericial, por ejemplo, la declaración de un vidente como un dictamen parapsicológico sería completamente inidóneo como medio de prueba ${ }^{24}$, al igual que la observación de los pájaros practicada en Roma por los augures, por los oráculos, en sesiones espiritistas o astrológicas o luego en los juicios del féretro ${ }^{25}$. La importancia del tratamiento de este criterio para este trabajo es que los autores han llamado la atención de que, por ejemplo, la completa inidoneidad debe apreciarse de forma restrictiva y cuidada, pues no se debe con ello realizar una

\footnotetext{
19 Las FRE dispone "Rule 401 - Test for Relevant Evidence. Evidence is relevant if:(a) it has any tendency to make a fact more or less probable than it would be without the evidence; and, (b) the fact is of consequence in determining the action".

20 Montero (2005) p. 151.

21 Montero (2005) p. 156.

22 Montero (2005) p. 156.

23 Göbel (2013) p. 175; Peters (1985) pp. 309 y 310.

24 Roxin (2000) p. 387.

25 Cordero (2006) p. 47.
} 
actividad que signifique un adelantamiento de la valoración de la prueba ${ }^{26}$. En otro sentido, UBERTIS, equipara idoneidad a relevancia probatoria ${ }^{27}$.

\section{CRITERIOS DE DEPURACIÓN EPISTÉMICA EN LA DOCTRINA LATINOAMERICANA}

Algunos autores del consorcio latinoamericano dan cuenta de un cierto sincretismo entre las tendencias anglosajonas y continentales en la materia. Entre otras razones, porque la cuestión de la "relevancia" de la prueba es algo común a diversos sistemas de enjuiciamiento ${ }^{28}$.

Así, CafFerata considera que la idoneidad conviccional es conocida como "relevancia" o "utilidad" de la prueba ${ }^{29}$. Para JAUChEN, la utilidad de la prueba está directamente relacionada con la relevancia que el elemento tenga con relación al objeto que deba probar$\mathrm{se}^{30}$. Para Maier, la utilidad es llamada en ocasiones relevancia, y no se mide por un solo parámetro $^{31}$. Especialmente uno de los sentidos, según el mismo autor, está vinculado con características empíricas. Ello ocurriría en el caso de los hechos notorios y sus significados próximos como cuando se permite excluir la prueba por evidente o manifiestamente superabundante o superflua ${ }^{32}$. Por su parte, para Binder, el tribunal tiene un poder de policía sobre el ofrecimiento de pruebas. Si la prueba es inútil, impertinente, superabundante o ilícita, el tribunal tiene la facultad de que esa prueba no se produzca. Para el mismo autor, la prueba inútil es aquella que no contiene información que sirva para probar las distintas hipótesis, a diferencia de la prueba impertinente, que contiene información no referida a la hipótesis de prueba $^{33}$. Para Horvitz y López, la prueba impertinente es aquella en que no existe ninguna relación lógica o jurídica entre el hecho y el medio de prueba ${ }^{34}$. Por su parte, Duce señala que la pertinencia de una prueba también puede ser conocida como la relevancia de la misma ${ }^{35}$. En este sentido, la pertinencia o relevancia admitiría dos niveles de análisis: el primero, la relevancia en el sentido lógico que ya le es tradicional; el segundo, el que denomina relevancia legal en la cual el juez debe pesar los aspectos favorables que la introducción de la prueba puede producir en juicio en contra de los potenciales perjuicios que pudiera generar la incorporación al mismo (análisis de costo-beneficio) ${ }^{36}$.

Todo lo anteriormente anotado da cuenta de ciertas asunciones que conviene ser explicitadas. En primer lugar, la preocupación de depuración epistémica no es algo propio ni exclusivo de la teoría racionalista de la prueba de corte anglosajón ${ }^{37}$. De hecho, ni siquiera

\footnotetext{
26 Peters (1985) p. 309; KüHne (2015) p. 508.

27 Ubertis (2017) p. 118.

28 TARUfFo (2008) p. 38. En relación con el common law, véase, RoberTs y ZuCKERMAN (2010) pp. 99 ss.

29 Cafferata (1998) p. 22

30 JAUCHEN (2006) p. 25.

31 Maier (1996) p. 93

32 Maier (1996) p. 93.

33 Binder (1999) p. 258

${ }^{34}$ Horvitz y López (2004) p. 45

35 Duce (2017) p. 57.

36 Duce (2017) p. 59. En un sentido similar, Hernández (2010) pp. 43 y s.

37 En este sentido, TARUffo (2010) p. 174; DAMAŠKa (1995) p. 348.
} 
tampoco lo son -per se- las reglas de exclusión ${ }^{38}$. De ello dan cuenta los conceptos de utilidad, pertinencia e inidoneidad de la prueba. En segundo lugar, los conceptos de relevancia, impertinencia, inutilidad e inidoneidad muestran que la cuestión del control epistémico de la prueba en sede de admisibilidad no puede desconocer su carácter relacional. Es decir, una estrecha conexión, -mayoritariamente asumida como una relación lógica- entre la prueba y el enunciado fáctico a acreditar como parte integrante del thema probandum. En tercer lugar, la confluencia de tradiciones y la amplitud del entendimiento del concepto de relevancia muestran que, quizás, en la delimitación del mismo, también entran en juego elementos extraepistémicos ${ }^{39}$.

En suma, pareciere ser común a todos los criterios de depuración probatoria en sede de admisibilidad la circunstancia que la prueba que debiera ser admisible sea aquella cuya información presente una conexión lógica con los hechos del caso, y que pueda aportar a la determinación de la probabilidad de acaecimiento, aunque sea de forma mínima. A lo primero llamaremos relevancia "lógica" o "formal"; a lo segundo, relevancia "probabilística" o "material".

\section{OTROS INTERESES CONFLUYENTES EN LA EXCLUSIÓN PROBATORIA}

Para determinar el alcance normativo de las reglas de exclusión por razones epistémicas, y su posible principio inclusivo, es necesario determinar los otros intereses que pueden entrar en conflicto en sede de admisión. Así, los más importantes en la materia, a mi modo de ver, son el derecho a la prueba y/o debido proceso, la titularidad de la decisión sobre los hechos, una diferenciación de la competencia epistémica entre diversos tribunales que conocen de cuestiones probatorias y el empleo de las reglas de exclusión como método de diseño específico de distribución del riesgo de error.

\section{Derecho a la prueba y/O DEBIDO PROCESO}

El derecho a la prueba está constituido por la garantía que reconoce a cualquier ciudadano con derecho de acción a aportar los medios de prueba que estime idóneos para apoyar su pretensión en juicio. El derecho de acción, canalizado a través de un derecho de tutela judicial, sería una previsión inútil, una garantía de letra muerta, si no se permitiera a los ciudadanos apoyar sus pretensiones con los medios de prueba que ellos mismos consideren óptimos para tal efecto. Ello, por lo demás, no es una habilitación ilimitada, en cuanto los medios de prueba ofrecidos y aportados deben ser relevantes y/o pertinentes para resolver el thema probandum. En este sentido, las reglas de exclusión también pueden ser vistas como una limitación al derecho a la prueba que, como tal, debe estar justificada de acuerdo con los cánones del sistema jurídico al que pertenece.

A mi modo de ver, los esfuerzos interpretativos más importantes incluyen el derecho a la prueba en el ámbito de protección del debido proceso que se encuentra consagrado

\footnotetext{
38 DAMAŠKa (2015) p. 33.

39 Como sucede con el testimonio de oídas. Véase, Ferrer (2007) p. 44.
} 
en el artículo 19 No 3 inciso sexto de la Constitución Política de la República de Chile ${ }^{40}$. En este sentido, la Comisión de Estudios de la Nueva Constitución dejó constancia que entendía que las garantías mínimas del debido proceso eran a lo menos: un oportuno conocimiento de la acción por parte del demandado, una defensa racional y adecuada, y la posibilidad de producir las pruebas cuando sea conducente ${ }^{41}$. El derecho a la prueba es una exigencia de justicia de la decisión jurisdiccional, por lo que asiste a este una aplicación amplia (incluido el Ministerio Público ${ }^{42}$ ) y no solo referida al imputado ${ }^{43}$. Así, la CS ha señalado que "En torno a los aspectos que abarca el derecho del debido proceso, no hay discrepancias en aceptar que a lo menos lo constituyen el derecho de ser oído, de presentar pruebas para demostrar las pretensiones de los intervinientes y de recurrir contra toda sentencia que estime agraviante a sus derechos. De esta manera, el derecho de probar los aspectos de hecho de las cuestiones en discusión es consustancial a la racionalidad y justicia de todo procedimiento y, por consiguiente, nadie puede arbitraria o ilegalmente privar a uno de los litigantes de la facultad de presentar y obtener la posibilidad de demostrar sus pretensiones" ${ }^{44}$. En un sentido similar se ha pronunciado el Tribunal Constitucional ${ }^{45}$. Igualmente, TARUFFO considera que el derecho a presentar todos los medios de prueba relevantes que estén al alcance de las partes es un aspecto esencial del derecho al debido proce$\mathrm{so}^{46}$. Algunos autores nacionales también adhieren a esta última postura ${ }^{47}$.

Ahora, el artículo 19 No 3 inciso 6 CPR, en su última parte, expresamente exhorta al legislador a dispensar una protección de la garantía, lo que también incluye la determinación de las limitaciones a la misma. Es decir, al tratarse de un derecho fundamental, su limitación solo debe ser establecida por medio de la ley, y de una forma que no se afecte su núcleo de protección iusfundamental como una forma de optimizar su operatividad. Ello alcanza -sin duda- al debido proceso y al derecho a la prueba, cuestión que sugiere, bajo esta perspectiva, considerar las reglas de exclusión probatoria como un medio de establecer dichas limitaciones.

\section{DIFERENCIACIÓN DE TRIBUNALES Y SUS COMPETENCIAS COGNITIVAS}

El JG, al resolver cuestiones sobre la admisibilidad de la prueba, con ello también afecta directa o indirectamente la decisión probatoria del caso que debe llevar a cabo el TJOP. ¿Por qué la identificación de una prueba epistémicamente deficiente debe someterse

\footnotetext{
40 Artículo 19 No 3 inciso sexto CPR: "Toda sentencia de un órgano que ejerza jurisdicción debe fundarse en un proceso previo legalmente tramitado. Corresponderá al legislador establecer siempre las garantías de un procedimiento y una investigación racionales y justos".

41 Biblioteca del Congreso nacional (1975) p. 556; Carocca (2002) p. 24.

42 En el mismo sentido, Maturana y Montero (2017) p. 46. También, Ministerio Público con Rigoberto Villablanca (2005).

43 Como parte del debido proceso en relación con el derecho de defensa, véase, Bordalí (2016) p. 206.

44 Ministerio Público con Rigoberto Villablanca (2005); Andrea Cifuentes con Belén Andrades y otros (2016), entre otras.

45 Requerimiento de inaplicabilidad (2017); Requerimiento de inaplicabilidad (2015); Requerimiento de INAPLICABILIDAD (2014), entre otras.

46 TARUfFo (2008) p. 56.

47 Por ejemplo, Maturana y Montero (2017) p. 42; Chahuan (2012) p. 27; Valenzuela (2017) p. 130.
} 
a un primer filtro en sede de admisibilidad? ¿Cómo podría justificarse epistémicamente ello? ¿Cómo se aborda la cuestión en el common law?.

La configuración normativa de las reglas de prueba en el ámbito anglosajón está vinculada con la manera en que se aplican; es decir, con su contexto institucional ${ }^{48}$. En un principio, la mayoría de las reglas de exclusión del common law dependen en buena medida de que la decisión sobre los hechos sea adoptada por un jurado lego ${ }^{49}$. De forma más precisa, en lo anterior impacta la interacción entre jueces profesionales y jueces legos que, cuanto más pronunciada es la separación entre estos dos tipos de juzgadores, el clima institucional se muestra más proclive a la utilización de reglas de exclusión con la finalidad de sustraer información al jurado, incluso, predefiniendo la forma en cómo se debe valorar la prueba a través de ciertas instrucciones ${ }^{50}$. Dichas reglas tendrían como fundamento evitar que los miembros del jurado atribuyan un peso epistémico distorsionado o equívoco ${ }^{51}$. Es decir, con ello se busca reducir el riesgo de error en la decisión sobre los hechos. Wigmore señalaba que los principios de la prueba representan el proceso natural de la mente en relación con "the evidential facts" después de que ellos son admitidos por el jurado, mientras que las reglas de admisibilidad son reglas particulares y artificiales para el sistema angloamericano del jurado ${ }^{52}$. RoBERTS y ZuCKERMAN señalan que el juez de la fase intermedia está en una posición para limitar el alcance de la discreción del jurado, para volver a veredictos cuestionables, a través de la exclusión de la prueba perjudicial no fiable o injusta, la cual podría llevar al jurado por un mal camino y así socavar la precisión factual de la adjudicación en materia penal ${ }^{53}$.

Ahora, esta desconfianza en la capacidad cognitiva del jurado ${ }^{54}$ podría -también- explicar los fundamentos de la decisión Daubert en Estados Unidos en materia de exclusión de la prueba pericial científica por ausencia de cientificidad. Dicho fallo reconoce que el juez tiene la función de "gatekeeper" o custodio de la calidad de la prueba, pues se asume que un jurado compuesto por legos o laicos presenta menores competencias cognitivas para reconocer una prueba pericial científica de mala calidad, que pueda estar amparada por el sesgo de la "cientificidad" o "mito de la infalibilidad" ner al jurado en la ignorancia de la existencia de la información, a partir de datos que sean perceptualmente excluidos ${ }^{56}$. Así, se considera que la decisión Daubert ha servido para trasladar la cuestión de la valoración de la prueba pericial científica hacia la fase de admi-

\footnotetext{
48 DAMAŠKA (2015) p. 25.

49 Roberts y Zuckerman (2010), p. 93; Ferrer (2007) p. 44; Damaška (2015) p. 42; Twining (1997) p. 44;

Landsman (1990) p. 1149; DamašKa (1995) pp. 349 ss. En contra, Murphy (2010) p. 546.

50 DAMAŠKA (2015) p. 41.

51 Así, Duce (2010) p. 49; Ho (2008) p. 47.

52 Wigmore (1937) p. 5.

53 Roberts y ZuCKerman (2010) p. 75.

${ }^{54}$ HAND (1901) p. 54: "But how can the jury judge between two statements each founded upon an experience confessedly foreign in kind to their own? It is just because they are incompetent for such a task that the expert is necessary at all".

55 Véase, Gascón (2013) p. 182; Dwyer (2008) p. 2.

56 Ho (2008) p. 43.
} 
sibilidad, frente a las dudas que al respecto exhibe el jurado ${ }^{57}$. Ahora, la aplicación de los criterios Daubert, y sus presupuestos, han dejado varias dudas respecto de la solidez de sus fundamentos, porque no hay criterios de consenso que permitan distinguir adecuadamente lo que es ciencia de lo que no es (dilema de la demarcación ${ }^{58}$ ) por lo que, bajo una exclusiva mirada epistémica, es peligrosa la utilización de reglas de exclusión basada e inspiradas exclusivamente en dichos criterios. En efecto, estas interrogantes han llevado a algunos autores anglosajones a reinstalar el estándar previo en la materia ("Frye") ${ }^{59}$ o, a derechamente desconocer los criterios del fallo Daubert.

Damaška critica que las reglas de exclusión del evidence anglosajón puedan explicarse cabalmente a partir de la desconfianza de las capacidades cognitivas del jurado pues, entre otras consideraciones, ello se opondría tanto a la evolución histórica del derecho probatorio angloamericano como a la legitimidad democrática que se suele atribuir a que la decisión sobre los hechos -en el plano organizativo de la justicia- sea adoptada por un grupo compuestos por ciudadanos (jurado ${ }^{60}$. Todo ello precisa una suerte de matización: si se duda de la capacidad de los miembros del jurado para determinar los hechos, la formación técnica no inhibe completamente de dichos cuestionamientos a los jueces profesionales ${ }^{61}$. Las únicas reglas útiles al respecto serían aquellas que buscan blindar al jurado de información capaz de abrumar a sus miembros emocionalmente ("pruebas macabras"), como las que puedan generar una hostilidad y una excesiva simpatía ${ }^{62}$, por la falta de experiencia de los juzgadores. Ahora, si se repara en la forma especial de adopción de la decisión del jurado sobre los hechos (a partir de la unanimidad y por medio de un veredicto sin motivación ${ }^{63}$, deliberación en secreto, etc.), las reglas de exclusión pueden ser mejormente concebidas como instrumentos dirigidos a influir en la decisiones colectivas que se adopten al amparo de dicha forma de administración de justicia ${ }^{64}$. Así, las reglas de exclusión también podrían justificarse en la intención de reforzar -a priori- la legitimidad de los veredictos inmotivados de los jurados ${ }^{65}$.

Aun cuando Damaška pudiera estar en lo correcto y la necesidad de blindar a los jueces de una sobrevaloración epistémica asiste a jueces legos y letrados, ello no resuelve la justificación de que esta tarea necesariamente tenga que llevarse a cabo en fase anterior a Juicio Oral con la misma fuerza que la cuestión exhibe en el sistema de justicia penal norteamericano. Ello generaría una preferencia epistémica odiosa y peligrosa en la materia en favor de JG, una suerte de paternalismo epistémico, en defecto de quien en nuestro sistema tiene la titularidad de la decisión de los hechos: el tribunal de juicio oral en lo penal. ¿Por qué el juez de la fase intermedia está en una mejor posición para no solo detectar los po-

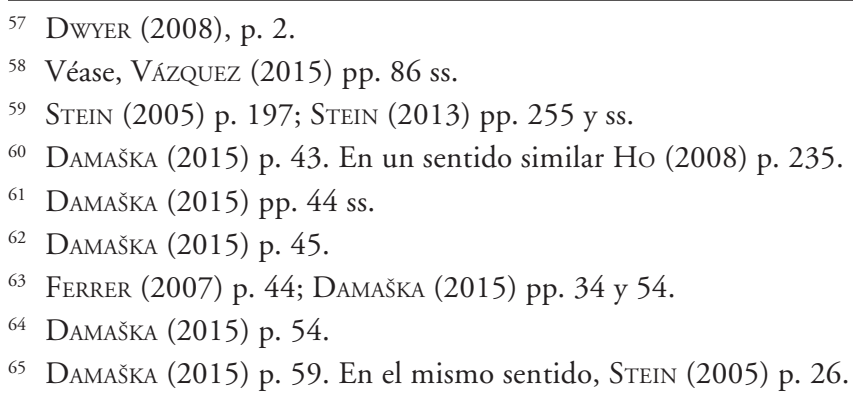


sibles sesgos de las pruebas -que parecieren no afectarle porque puede detectarlos (!)- sino también para excluir prueba a partir de una proyección de efectos perniciosos que ellos puedan generar en el TJOP? Excluyendo el control sobre los mínimos, no parecen haber buenas razones epistémicas para dicha diferenciación. Ahora, una razón plausible -que comparto- puede encontrarse en el efecto de "contaminación" que se generaría si el mismo tribunal que decide sobre los hechos, a su vez, conoce de la exclusión de la prueba ilícita ${ }^{66}$, por ejemplo. Sin embargo, en el mejor de los casos, ello trazaría una justificación de la aplicación de las reglas de exclusión por parte del JG -como tribunal diferenciado respecto del TJOP- pero solo respecto de las reglas cuyos fundamentos son genuinamente extraepistémicos. No logro apreciar igual efecto de contaminación respecto de la exclusión de prueba por motivos epistémicos. Ahora, distinto es si la detección de dichos mínimos se asume como una decisión política, en cuyo caso deben establecerse expresamente por la ley, pues esa es la vía idónea de distribución de intereses en juego.

Desde esta perspectiva, nuestro CPP en materia de reglas de exclusión ha dado al JG competencias para excluir aquellas pruebas que no cumplan con un grado mínimo de utilidad de la información. No creo replicable en nuestro sistema asumir una desconfianza cognitiva respecto de la valoración de la prueba que hace el TJOP ni una necesidad de legitimar su decisión por la vía de la robustez de las reglas de exclusión como sucede con el jurado angloamericano.

3. La titularidad de la decisión sobre los hechos. Diferencias entre el juicio DE ADMISIÓN Y VALORACIÓN DE LA PRUEBA

En el modelo de enjuiciamiento del CPP la decisión jurisdiccional sobre los hechos del caso es de titularidad exclusiva del TJOP y ello, sin duda, ha impactado en la estructura procedimental. En efecto, las atribuciones del JG son especialmente limitadas respecto del control de fondo de la acusación y la oportunidad de su ejercicio en coherencia con esta distribución estructural, porque el CPP asume un modelo preparatorio de etapa intermedia con elementos decisionales aislados ${ }^{67}$. Así, especialmente en lo referido a la depuración probatoria, el CPP acoge la distinción entre admisión y valoración probatoria, entregando la primera la JG en fase intermedia y la segunda a TJOP. Con ello se blinda a esta último de la contaminación que se pueda dar en el caso que, además de valorar, tuviera que resolver, por ejemplo, de la cuestión de la prueba ilícita.

Podríamos cuestionar y debatir si efectivamente la "admisión" de los medios de prueba es algo cognitivamente diferenciado y distanciado de la "valoración probatoria" propiamente tal $^{68}$. Como veíamos, muchos filtros de admisibilidad consideraban incluidos en ellos cuestiones más propias de la valoración de la prueba, como la apreciación de la credibilidad de ciertos testigos. Sin embargo, el CPP asume dicha diferenciación, poniendo límites y características especiales de una en relación con la otra. La intención legislativa se centra, a mi modo de ver, en el interés de cautelar que, no obstante, se excluyan pruebas

\footnotetext{
66 Véase, DAMAŠKa (1995) p. 352.

67 VERA (2017) p. 171.

${ }_{68}$ En este sentido, Ho (2008) p. 33.
} 
por motivos epistémicos y extraepistémicos, esto por ningún modo debe constituir un prejuzgamiento de la cuestión de los hechos de forma de evitar un adelantamiento de la valoración probatoria propia de la fase de Juicio ${ }^{69}$. El JG resuelve sobre la exclusión solicitada sobre la base de antecedentes que son germinales en relación con el concepto jurídico de "medio de prueba" (rendidos en juicio oral bajo contradicción), constituyendo con ello una decisión conectada que afecta la valoración probatoria, pero claramente diferenciada de esta última. Ello podría explicar por qué en sede de admisión no hay prueba sobre las causales de exclusión de la prueba. De otro lado, sin razón aparente, el régimen recursivo respecto del auto de apertura de juicio oral es limitadísimo, no pareciendo cubrir la revisión de la decisión de exclusión por razones epistémicas, dejando a salvo por cierto el recurso de nulidad. Ello nos lleva a pensar que la labor epistémica del JG es limitada y mínima atendiendo al diseño estructural del proceso penal chileno.

Ahora, desde el punto de vista del discurso justificatorio de la decisión en lo relativo a los hechos, hay algo que estructuralmente falta en fase intermedia en lo relativo a la admisión probatoria: la valoración conjunta o visión holista o coherencial de la cuestión de los hechos ${ }^{70}$, a partir de la rendición y contradicción de todos los medios de prueba. Si se quiere, la cuestión de la exclusión de la prueba en fase intermedia se desarrolla en el CPP asumiendo una perspectiva epistémica exclusivamente atomista o particular de cada medio de prueba cuando muchas veces, para valorar un antecedente en particular, hace falta vincularlo con la información proporcionada por otro medio de prueba en un sentido ex post. Quizás por eso se afirma que la decisión sobre la admisibilidad de los medios de prueba es una cuestión hipotética ${ }^{71}$ o que solo se puede resolver ex ante.

Por su parte, una perspectiva holista -complementaria a la atomista- puede identificarse claramente en sede de juicio oral al exigir al tribunal hacerse cargo de toda la prueba, y no solo de la útil para fundar su pretensión (art. 297, inciso $2^{\circ} \mathrm{CPP}$ ). Repárese en lo importante de esto. Un buen cúmulo de casos complejos, especialmente en los contextos de escases probatoria, obligan a recurrir a la prueba circunstancial o indirecta -ad initio conjunta- para dar por acreditado un supuesto donde no hay prueba directa o donde esta no puede llegar (p. ej. la prueba del dolo). O, desde otra perspectiva, algunos casos probatoriamente complejos obligan a echar por tierra limitaciones derivados de nuestra formación jurídica (p. ej. testes unnus testes nullus en el caso de las condenas basadas en el testimonio de la víctima). Todas las cuestiones anteriores, a mi juicio, pueden abordarse desde el punto de vista del peso de la prueba de mejor forma en sede de juicio oral. Ello muestra que un control de admisibilidad ex ante robusto, basado en exclusiva en un enfoque atomista, puede ser extremadamente peligroso más allá de los mínimos.

De otro lado, también influye en la cuestión en comento un rasgo propio de los procedimientos penales de herencia románica continental: la motivación de la decisión de los hechos y su posibilidad de control ex post facto ${ }^{72}$. Lo primero, sin duda, es una forma

\footnotetext{
69 Kühne (2015) p. 508; Denbeaux y Risinger (2003) p. 23.

70 Valenzuela (2017) p. 105.

71 Taruffo (2008), p. 39; Horvitz y López (2004) p. 46; Ubertis (2017) pp. 114 ss.

72 Ferrer (2007) p. 44; Igartúa (2013) p. 21; Ferrer (2010) p. 17.
} 
de control de las asunciones sobre la prueba y los hechos que, específicamente en nuestro sistema, debe ser acordada por un tribunal colegiado. Como se puede apreciar, este tipo de control puede ser considerado un filtro a posteriori de la calidad epistémica de la prueba en relación con los hechos ${ }^{73}$. Precisamente, esta perspectiva es mayoritariamente ausente en los enjuiciamientos por jurado. De ello podría derivarse la justificación de que en el ámbito del common law se de tanta importancia a las reglas de exclusión, apareciendo ellas configuradas de una manera robusta ${ }^{74}$, porque la adopción de la decisión del jurado es algo misterioso, muchas veces incontrolable, que a veces se le ha comparado con la mecánica operativa de las ordalías ${ }^{75}$. Por ello se señala que la motivación del veredicto por parte de los jurados privaría de justificación a los recortes en la práctica de la prueba, ya que aquella serviría de contención a los sesgos y permitiría detectar a posteriori el influjo de todas ellas y de ser neutralizadas por el procedimiento que corresponda ${ }^{76}$. Hasta los comentaristas angloamericanos más escépticos reconocen que la exteriorización de las razones hace el ejercicio del poder de decisión sobre los hechos algo menos impenetrable frente a un veredicto inmotivado ${ }^{77}$, pese a que este último en ningún caso habilitó para que los jurados adoptaran decisiones irracionales acerca de los hechos ${ }^{78}$. Así, la motivación en relación con los hechos admitiría un test de validez ${ }^{79}$, de forma que su control también lo es respecto a cómo el juez da por probado los hechos. Con ello se quiere aludir cuando se dice que la decisión sobre los hechos se expresa en un razonamiento que tiene una función demostrativa ${ }^{80}$ que, además, puede y debe ser intersubjetivamente controlable. Así, considerando la motivación como control epistémico ex post facto, decae la necesidad de que la cautela epistémica se de casi en exclusiva en fase intermedia, como sucede en los juicios por jurado. Ello también acarrea otra exigencia en nuestro sistema: todo lo que tenga que ver con la valoración de la prueba y la decisión del asunto, en un contexto normativo que obligue a los jueces a motivar sus decisiones, no debe ser abordado anticipadamente en el momento de la selección del material probatorio ${ }^{81}$.

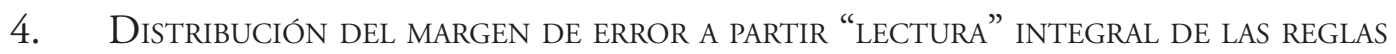 PROBATORIAS DEL CPP}

El escenario epistémicamente inhóspito que el legislador muchas veces enfrenta al establecer reglas probatorias muestra que muchas de ellas también presentan componentes decisionales políticos y/o morales. Ello pone en contacto a las reglas de exclusión intrínseca con intereses o valores extraepistémicos.

\footnotetext{
73 En este sentido, Ferrer (2010) p. 17.

74 DAMAŠKa (2015) p. 59.

75 Así, TARufFo (2010) p. 36.

76 Igartúa (2013) p. 21.

77 DAMAŠKA (2015) p. 58.

78 Ho (2008) p. 37.

79 TARUfFo (2011) pp. 234 y s.

80 Así, Igartúa (2003) p. 147.

${ }^{81}$ Ferrer (2007), pp. 42 ss.
} 
En este sentido, la articulación de las diversas reglas probatorias en el proceso penal, especialmente las reglas de exclusión y/o de satisfacción de estándar de prueba, parecen un instrumental utilizado por el legislador para distribuir adecuadamente el riesgo de error respecto de la decisión sobre los hechos, en atención a las serias y graves consecuencias penales derivadas de una condena. De hecho, la labor de decisión sobre los hechos en un contexto de incertidumbre siempre conlleva un riesgo de error, que se asigna y administra a través de las reglas que permiten admitir o excluir prueba o a partir de las que determinan un estándar de prueba que debe satisfacerse ${ }^{82}$. En efecto, según STEIN, las razones que identifican a la situación probatoria portadora del riesgo de error y determinan la medida en que ellas se realizarán presentan un carácter moral y político ${ }^{83}$. Muchas veces la asignación del riesgo de error viene a graficar la decisión que los jueces deben tomar en orden a asentar los hechos precisamente allí donde los criterios epistémicos fallan ${ }^{84}$. En este sentido, si se quiere, la moral recoge allí donde la epistemología deja fuera ${ }^{85}$.

Esta visión de conjunto o de sistema de reglas distributivas del riesgo de error se altera cuando en la interpretación de un precepto se torna en exceso particularista, desconociendo con ello la visión sistemática de su normatividad en materia probatoria.

Las reglas probatorias aplicables en fase intermedia son un presupuesto o condición normativa de la aplicación de las normas que cierran el sistema probatorio, como las que regulan el estándar de prueba. Así, si la interpretación poco precisa de las reglas de exclusión intrínsecas de fase intermedia redunda en una robustez injustificada de las mismas, ello también puede afectar a la aplicación del estándar de prueba, distorsionándolo y, quizás, haciéndole más exigente que lo originariamente querido. La prueba, en este sentido, es siempre contextual, por lo que, si cambia el conjunto, por adición o sustracción de algún elemento, el resultado puede ser perfectamente otro ${ }^{86}$.

La alteración del sistema de distribución del riesgo de error contenidas de las normas probatorias puede generar resultados indeseados o, derechamente, un daño ${ }^{87}$. Ello podría explicar por qué algunos autores abogan que las reglas probatorias debieran ser más estrechas que laxas ${ }^{88}$, para alterar en lo mínimo posible el material probatorio disponible puesto al servicio de la decisión sobre los hechos. Desde esta perspectiva, la robustez injustificada de la relevancia, por ejemplo, puede condicionar de forma indeseada la decisión final sobre los hechos.

También es una atribución legislativa administrar el riesgo de error de la decisión probatoria en relación con otros intereses. En este sentido, la exclusión de prueba también podría estar motivada por razones de economía procesal o correcta inversión de los fondos públicos en el ejercicio de la jurisdicción. La doctrina procesal señala que el proceso, que es

\footnotetext{
82 STEIN (2005) pp. 12 y 127; STEIN (2013) p. 251.

83 STEIN (2005) p. 13.

84 STEIN (2005) p. 13.

85 STEIN (2005) p. 13.

86 Ferrer (2010) p. 8.

87 STEIN (2005) p. 16, en un sentido similar, lo asume planteando que el vínculo utilitario en prueba y regla supresiva y la asimetría entre falsos positivos y falsos negativos puede producir un daño.

88 STEIN (2005) p. 118.
} 
un medio, no puede exigir un dispendio superior al valor de los bienes que están en debate, que son un fin. Así, una necesaria proporción entre fin y los medios debe presidir la economía del proceso, siendo una aplicación de este principio la limitación de las pruebas en ciertos supuestos ${ }^{89}$. Para TARUfFo, la justificación básica del criterio de relevancia, por ejemplo, es práctica, y se funda en normas de economía procesal: frustra probatur quod probatum non relevant ${ }^{90}$. Ello, entre otras razones, porque implica la posibilidad de excluir prueba que no hubiese resultado útil para determinar los hechos y, por consiguiente, no impone limitación a la selección de las informaciones que sirven para determinar la verdad ${ }^{91}$.

De otro lado, ello también podría ser la justificación de la exclusión de la prueba sobreabundante, inútil o la referida a hechos públicos o notorios ${ }^{92}$, o en todos los casos en que el medio de prueba, pese a ser relevante, no es eficiente y/o necesario ${ }^{93}$-en concretopara aportar información de importancia para la resolución del thema probandum.

En este sentido, en el contexto del proceso penal chileno, la concreción de la decisión de esta distribución de intereses y del riesgo de error es una atribución exclusivamente legislativa ${ }^{94}$, que se expresa a partir de normas probatorias específicas, concretas y delimitadas, siendo ello coherente con la limitación que implican las reglas de exclusión respecto del derecho a la prueba.

\section{EL PRINCIPIO DE LA INCLUSIÓN DE PRUEBA RELEVANTE COMO CRITERIO RECTOR DE DEPURACIÓN EPISTÉMICA EN SEDE DE ADMISIÓN EN EL CPP CHILENO}

\section{PeRsPeCtiVAS ePISTÉMICAS}

El evidence anglosajón ha sido tradicionalmente visto como un conjunto de reglas de exclusión, que cualifican el principio general que toda prueba relevante debe ser presentada ante los jueces que adoptan la decisión sobre los hechos ${ }^{95}$. El principio de inclusión de la prueba relevante señala que toda la prueba relevante debe ser admitida a juicio. Y este, a su vez, ha sido conceptualizado como uno de los rasgos más importantes del "Anglo American Evidence Scholarship” que ha dominado la discusión probatoria a lo largo de todo el siglo $\mathrm{XX}^{96}$.

Para Bentham, la exclusión de toda prueba sería la exclusión de toda justicia ${ }^{97}$. La razón de ello arrancaría en que la prueba de los hechos es una cuestión epistemológica en

\footnotetext{
89 Couture (2005) p. 155

90 Taruffo (2008) p. 39; Taruffo (2010) p. 163; Horvitz y López (2004) p. 45; Ubertis (2017) p. 117.

91 Taruffo (2010) p. 163.

92 Sobre la prueba referida a los hechos notorios, véase, STEIN (1990) pp. 133 ss. Su exclusión como ejemplo del principio de economía, véase, Couture (2005) p. 193. En relación con la justificación de la prueba superflua, véase, TARUfFO (2010) p. 164.

93 Ello se puede ver, entre otras cosas en la vinculación que hace COUTURE (2005) p. 191, de la prueba sobre el hecho notorio con el aforismo notoria non egent probatione.

94 STEIN (2005) p. 16.: "Moral and political controversies over the apportionment of the risk of error ought to be resolved by the law".

95 Roberts y ZuCKerman (2010) p. 73.

96 Twining (2006) p. 210; Jackson y Summer (2012) p. 37.

97 Bentham (2001) p. 391. Véase, Landsman (1990) p. 1177.
} 
donde el derecho no tiene mayor cabida. Desde esta perspectiva, las reglas de exclusión expresarían un mal, al igual que las penas ${ }^{98}$, por lo que hay que limitarla a los mínimos posibles. BENTHAM, en materia de prueba, retorna hacia el natural sistema de prueba libre, basado en la experiencia diaria en el razonamiento de sentido común ${ }^{99}$, entendiendo que en la apreciación de la prueba no tienen cabida las reglas probatorias. De ahí que a esta corriente se la denomine abolicionismo probatorio ${ }^{100}$. Así, la reconstrucción que hace BENTHAM de las reglas de exclusión señala que estas pueden estar basada en los siguientes motivos: a) para desechar los testimonios engañosos, b) para prevenir las dilaciones, los vejámenes y los gastos que resultarían de la admisión de tales o cuales testimonios. Agrega: "El primero de estos motivos, mal fundado; el segundo, justo y razonable"101. Desde esta perspectiva, la exclusión es admisible si satisface la condición de excluir prueba irrelevante, superflua o cuando su producción podría involucrar vejámenes, dilaciones o costos excesivos, desde la perspectiva del estándar de utilidad ${ }^{102}$. Considera, además, que encontrar reglas de prueba infalibles a partir de las cuales se asegure una decisión correcta, desde el punto de vista de la naturaleza de las cosas, es absolutamente imposible. La mente humana es demasiado susceptible a establecer reglas las cuales incrementan las probabilidades de malas decisiones ${ }^{103}$. BENTHAM se opuso a la existencia de las reglas de exclusión que gobiernen la credibilidad, peso y quantum de la prueba ${ }^{104}$ porque todas ellas son en alguna medida negativas o traviesas ("mischievous") $)^{105}$.

Ahora, la restricción del ámbito aplicativo de las reglas de exclusión se basa mayoritariamente en la asunción que la probabilidad de alcanzar una decisión correcta respecto de la verdad sobre los hechos aumenta en la medida en que lo hace la información de lo ocurrido ${ }^{106}$.

En este sentido, en un proceso ideal, el principio de relevancia sería suficiente con toda probabilidad para filtrar adecuadamente la prueba en atención a maximizar la finalidad de la búsqueda de la verdad ${ }^{107}$. Así, el criterio que debiera regir la investigación es el de la búsqueda de información libre y sin restricciones, que se ha formulado a través de la historia de las instituciones jurídico-probatorias a través de reglas epistemológicas que reconoce la función inclusiva de la relevancia ${ }^{108}$. Se trata de obtener un cúmulo de elementos de juicio (o pruebas) lo más rico posible, entendiendo que ello se satisface cuando el proceso

\footnotetext{
98 Bentham (2001) p. 398.

99 Twining (1985) p. 3; STEIn (2005) p.109.

100 En este sentido, Ferrer (2010), p. 5.

101 Bentham (2001) p. 441.

102 Bentham (1843), VI, p. 89 ss; Twining (1985) p. 68.

103 Bentнам (1825) p. 180. En el original: "To find infallible rules for evidence, rules which insure a just decision is, from the nature of things, absolutely impossible; but the human mind is too apt to establish rules which only increase the probabilities of a bad decision. All the service that an impartial investigator of the truth can perform in this respect is, to put the legislators and judges on their guard against such hasty rules".

104 Ferrer (2010) p. 4.

105 TWINING (1985) p. 43.

106 Ferrer (2010) p. 12.

107 TARUfFo (2010) p. 165.

108 En este sentido, GASCÓn (2010) p. 116.
} 
judicial facilita la incorporación al proceso del máximo número de pruebas relevantes ${ }^{109}$. Así vista, la relevancia es una condición de la admisibilidad probatoria ${ }^{110}$.

Para LAUDAN, excluir pruebas relevantes, y no redundantes, por la razón que sea, disminuye la probabilidad de que personas, en principio, racionales lleguen a conclusiones correctas ${ }^{111}$.

Por su parte, STEIN critica la asunción Benthamiana de que "más prueba es mejor", porque no hay ni puede haber un paralelo cuantitativo entre la información completa e incompleta de un caso $^{112}$. De otro lado, porque lo que importa es una valoración cualitativa de la prueba y no se pueden establecer - a priori- consecuencias epistémicas a partir de criterios cuantitativos de los elementos disponibles, además, como reverso, porque el concepto de información incompleta es ubicuo ${ }^{113}$. Más bien, lo importante y trascendente en este caso es la identificación de riesgos de errores tolerables e intolerables ${ }^{114}$. Por el contrario, TARUfFO señala que las críticas a Bentham pueden llegar a ser ciertas, pero también lo es que excluir la posibilidad de utilizar pruebas relevantes es una forma segura de excluir la posibilidad de descubrirla ${ }^{115}$. En este sentido, no hay que dejar de confiar en que la probabilidad de la información disponible podría minimizar los resultados erróneos considerando la extensión temporal de muchos casos ${ }^{116}$. En efecto, reglas de exclusión demasiado robustas pueden generar una falsa sensación de confianza respecto de la evitación de los errores en lo que respecta a la decisión sobre los hechos ${ }^{117}$.

El programa epistémico contenido en el procedimiento penal es definido por el legislador ${ }^{118}$. Sin embargo, no puede desconocerse que, prescindiendo de la exactitud de lo ocurrido, tal parece ser que el aumento de la información relevante incrementa la probabilidad de que adopte una decisión adecuada materialmente, considerando probados enunciados verdaderos sobre los hechos ${ }^{119}$. Así, si alguna importancia tiene la búsqueda de la verdad como interés epistemológico propio del modelo cognoscitivista, ello impone una contención a las fórmulas legales de limitación de prueba, y allí donde no exista limitación expresa, una interpretación favorable a la "entrada de la verdad en el proceso" ${ }^{20}$.

Para mí, desde una mirada inicialmente epistémica, el CPP adopta el principio de la inclusión de la prueba relevante, entendiendo, a su vez, relevancia y/o pertinencia en el doble sentido ya desarrollado y que reúne el espíritu de los criterios de los filtros que en

\footnotetext{
109 Ferrer (2007) p. 68.

110 Burgess-JaCkson (1986) p. 466; Thayer (1898) p. 266.

111 LAUDAN (2013) p. 46.

112 En un sentido similar, HAACK (2008) p. 58: "It doesn't follow that more evidence is always better than less, so that the policy should be to let it all in; for additional-but-still-incomplete evidence may lead us in the wrong direction, while the previously available even-more-incomplete evidence would have led us in the right direction".

113 STEIN (2005) p. 123.

114 STEIN (2005) p. 123.

115 Taruffo (2010) p. 166. En el mismo sentido, Hernández (2010) p. 38; Ferrer (2010) p. 9.

116 DAMAŠKA (1995) p. 355.

117 TWInING (1985) p. 70.

118 Para Ho (2008) p. 47, el juicio es estudiado como un proyecto de epistemología naturalizada.

119 Ferrer (2010) p. 15.

120 GASCÓn (2010) p. 120.
} 
ámbito del civil y common law se han utilizado para ello: relevancia en un sentido lógico y la relevancia en su sentido probabilístico. La relevancia en su sentido lógico o formal, como relación de la información con el thema probandum, es una cuestión ínsita a la valoración racional de la prueba (no una regla artificial ${ }^{121}$, más bien de acuerdo con el estándar de la experiencia general ${ }^{122}$ ), y puede ser estimada más bien como una precondición de la investigación lógica de los hechos. No se define con ello un concreto estándar de admisibilidad en su sentido probatorio ${ }^{123}$. La relevancia, en su sentido probabilístico o material, implica que la información emanada del medio de prueba sirva para determinar la probabilidad de acaecimiento de algunas de las hipótesis fácticas que componen el thema probandum. Redmayne señala que la prueba es relevante si puede ser entendida en los términos de la ratio de dos tipos de probabilidades: aquella referida la inocencia y aquella referida a la culpabilidad del acusado ${ }^{124}$. La propiedad probabilística de la relevancia como criterio de admisibilidad solo se satisface controlando que el medio de prueba contribuya a la determinación de la probabilidad de los hechos objeto del juicio, aunque sea en un mínimo sentido ${ }^{125}$. Esto último también se aviene con la cautela de la economía procesal en esta materia, como señalábamos. Todo lo que exceda del control de ese mínimo epistémico es materia de valoración de prueba, propia del juicio oral, y no podría calificarse incluida dentro de la fase de admisibilidad, porque, además con ello se tensiona el derecho a la prueba de los intervinientes. Tampoco parece un lugar adecuado incluir dentro de la relevancia cuestiones más propias de consideraciones genuinamente extraepistémicas, como lo que la doctrina ha denominado "relevancia legal". El complejo escenario normativo donde las reglas de exclusión operan no parecen ser compatibles con interpretaciones que cobijen o amparen intereses morales o extraepistémicos que el legislador, atendido el debido proceso, debió consignar expresamente dentro de sus atribuciones que les son propias.

De otro lado, el principio de admisión de la prueba relevante sería la regla general, y la exclusión de la prueba irrelevante sería solo excepcional ${ }^{126}$, porque con ello se aviene mejor que la decisión de los hechos esté radicada en el TJOP y porque, además, un sentido general y amplio de este tipo de reglas de exclusión podría otorgar una posible atribución de paternalismo epistémico al JG, cuestión que se haya injustificada en nuestro sistema jurídico, como veíamos.

Además, la excepcionalidad de estas reglas de exclusión también asume que su utilización general puede llegar a ser peligrosa, no solo por condicionar el resultado probatorio final del juicio y por el peligro de constituir un prejuzgamiento de la cuestión, sino porque

\footnotetext{
121 Roberts y Zuckerman (2010) p. 101.

122 ThaYer (1898) pp. 265, 516.

123 Roberts y Zuckerman (2010) p. 98. En similar sentido, TARuffo (2010) p. 161, quien sostiene que es un principio epistémico obvio determinar la verdad de los hechos a partir de las informaciones útiles para dicho objetivo.

124 Redmayne (2002) p. 686.

125 Roberts y Zuckerman (2010) p. 101. Estos autores indican, si la probabilidad de "y" es una en 10 millones, $y$ la prueba de " $\mathrm{x}$ " incrementa la probabilidad en el minúsculo monto de otro uno en 10 millones, $\mathrm{x}$ es relevante respecto de $\mathrm{y}$.

126 Burgess-JaCKSON (1986) p. 466.
} 
la epistemología presenta conflictos internos acerca de la definición de los criterios respecto de cuándo una prueba es óptima o no. Recuérdese en este sentido la cuestión del dilema de la demarcación en el ámbito de la prueba pericial científica.

En efecto, per se, la exclusión presupone impedir el acceso del TJOP a cierta información, lo que en cierto punto dificulta la adecuada realización de la función jurisdiccional. Desde esta perspectiva, dichas reglas deben ser excepcionales, justificadas ${ }^{127}$ y de carácter restrictivo, porque en nuestro sistema quién decide sobre los hechos en el TJOP y se estaría condicionado de algún modo el cumplimiento de sus deberes. Twining señala que casi todos los cambios que se han ido introduciendo desde la época de Bentham van en dirección de abolir o disminuir la importancia de las reglas de exclusión, tendencia que ha ido más lejos en Inglaterra que en Estados Unidos, aunque el principio general de la no exclusión no ha sido aceptado ${ }^{128}$.

Así, frente a la cuestión epistémica, el legislador parece haber optado en sede de fase intermedia solo por el control de los mínimos epistemológicos de la prueba, que nosotros hemos llamado relevancia en su sentido lógico y probabilístico. Ello, por lo demás, parece apoyarse en que el legislador solo haya permitido la exclusión de no cualquier prueba impertinente, sino solo la "manifiestamente" impertinente, lo que sugiere el empleo de criterios de exclusión más o menos seguros, de carácter evidente ${ }^{129}$, y estrictos. Y ello se consigue, en mi opinión, aplicando el criterio de relevancia como filtro en los dos sentidos anotados. Lo anterior, además, es coherente con la potencia normativa en nuestro sistema jurídico del derecho a la prueba en relación con el debido proceso, considerando, a mayor abundamiento, la titularidad de la decisión jurisdiccional sobre los hechos y la posibilidad de control epistémico ex post a través de la motivación de la sentencia.

\section{PeRsPeCtivas NORMATIVAS}

En el proceso penal chileno los principales criterios que se refieren a la exclusión de la prueba por falta de calidad epistémica se sitúan en el artículo 276 CPP. En efecto, el citado artículo señala: "El juez de garantías, luego de examinar las pruebas ofrecidas y escuchar a los intervinientes que hubieren comparecido en la audiencia, ordenará fundadamente que se excluyan de ser rendidas en el juicio oral aquellas que fueren manifiestamente impertinentes y las que tuvieren por objeto acreditar hechos públicos y notorios". Es decir, como ya he señalado en reiteradas veces, el criterio general de depuración epistémica es el de "pertinencia" y/o "relevancia". El citado texto normativo contiene, además, una cláusula de cierre respecto de la admisión probatoria en su último inciso: "Las demás pruebas que se hubieren ofrecido serán admitidas por el juez de garantía al dictar el auto de apertura del juicio oral" (art. 276 parte final CPP). A través de la interacción entre estos dos enunciados normativos es que es posible entender que, por todo lo expuesto con anterioridad en este trabajo, el inciso final del citado artículo establece el principio general de la inclusión de la prueba relevante, que se muestra coherente con el aseguramiento del derecho a la prueba

\footnotetext{
27 Twining (1985) p. 70.

128 Twining (2006) p. 44; STEIN (2005) p. 196.

129 Horvitz y López (2004) p. 46.
} 
vinculado al debido proceso. Pero este principio de admisión de prueba se haya limitado por la exclusión de prueba manifiestamente impertinente. Con ello se termina por configurar el principio general de admisión de la prueba relevante, siendo únicamente posible excluir la que es irrelevante (manifiestamente impertinente). Desde esta perspectiva, se puede llegar a afirmar en nuestro sistema que la relevancia en materia de admisión es un criterio incluyente (función inclusiva), con prioridad lógica, de modo que las normas específicas cuyo objeto es excluir ciertos medios de prueba deben ser consideradas como excepciones a ese principio general ${ }^{130}$. Así, una prueba relevante debe ser excluida porque así lo prevé una norma específica ${ }^{131}$ que, además, debe estar debidamente justificada ${ }^{132}$.

Lo anterior, también debe ser confrontado con lo que señala el artículo 295 CPP cuando regula la libertad de prueba: "Todos los hechos y circunstancias pertinentes para la adecuada solución del caso sometido a enjuiciamiento podrán ser probados por cualquier medio producido e incorporado en conformidad a la ley". Como se ve, esta norma, señalando un principio general del sistema probatorio, hace referencia al criterio de la pertinencia, por un lado, y a ratificar el principio de admisión como corolario del derecho a la prueba, por otro.

Esta organización de enunciados normativos en la materia no es exclusiva de nuestro ordenamiento jurídico. El artículo 402 de FRE dispone: "Relevant evidence is admissible unless any of the following provides otherwise: The United States Constitution; a federal statute; these rules; or other rules prescribed by the Supreme Court. Irrelevant evidence is not admissible”. En efecto, como reconoce el Comité asesor de proposición de estas normas -valiéndose de las palabras de Thayer-, la provisión de que toda la prueba relevante es admisible, con ciertas excepciones, y que la prueba que no es relevante no es admisible, "es una presuposición contenida en toda la concepción de un sistema de prueba racional"133. En efecto, la doctrina señala que existe una especie de principio general de relevancia en todos los sistemas probatorios ${ }^{134}$. De otro lado, KIRKPATRICK considera consistente la regulación de las FRE con la posición de Bentham en los términos de aceptar la relevancia como criterio de admisión ${ }^{135}$.

Piénsese lo similar en términos estructurales de la regulación nacional y de las FRE. Si bien es cierto en el ámbito continental por un buen tiempo ha existido un rechazo a incorporar aportes normativos del common law, especialmente en materia de derecho probatorio, hay antecedentes que contribuyen a sembrar la duda al respecto ${ }^{136}$. Por otro lado, como anotaba, la cuestión de la relevancia y/o pertinencia ha sido común a los enjuiciamientos de diversas tradiciones jurídicas y, por lo bajo resulta llamativa la similitud estruc-

\footnotetext{
130 En este sentido, aunque refiriéndose a las FRE, TARUfFo (2008) p. 41; TARUfFo (2010) p. 163.

131 TARUfFo (2010) p. 167; Ferrer (2010) p. 7.

132 Hernández (2010) p. 23, pone de manifiesto que estas reglas son conceptualmente sospechosas y requieren siempre de una justificación especial y convincentes.

133 Thayer (1898) p. 264.

134 TARUfFo (2008) p. 39. Agrega, p. 41: “...no hay duda de que el principio de relevancia determina la primera condición general para la admisibilidad de las pruebas".

135 KirkPATRick (1992) p. 840.

136 Véase, Andrés (1992) p. 279; VÁsquez Sotelo (1984) p. 456.
} 
tural y la adaptabilidad del principio de inclusión de la prueba relevante a lo previsto por el CPP chileno ${ }^{137}$.

\section{Perspectivas EXTRAePistémicAs}

Otra forma de justificar el principio de inclusión de la prueba relevante en el CPP chileno es analizando la cuestión desde la perspectiva extraepistémica y/o moral aun cuando, en un principio, nos encontremos en el campo de una cuestión prima facie epistémica. En efecto, las reglas de exclusión de la prueba por motivaciones epistémicas también pueden ser un instrumento utilizado por el legislador para situar el riesgo de error de la decisión, como veíamos. Es más, STEIN llega a sostener que las reglas de prueba del ámbito anglosajón y sus principios asociados tienen una sola importante función: asignar o distribuir el riesgo de error ${ }^{138}$. De otro lado, Ho señala que la principal función de las reglas probatorias es controlar la deliberación al interior del juicio ${ }^{139}$. En efecto, la materialización del riesgo de error se traduce en un fallo erróneo que prive a alguien injustificadamente de sus derechos, por lo que el reparto del riesgo de error debe considerarse como una decisión ligada a valores ${ }^{140}$. Como señala Damaška, en materia probatoria, el empleo de procesos ordinarios de cognición no es simplemente una cuestión de preferencia epistémica, sino también de carácter político y ético ${ }^{141}$.

Con independencia de estas opiniones, es claro que muchas reglas de exclusión están basadas en motivaciones extraepistémicas, incluso aquellas que prima facie pueden ser conceptualizadas como epistémicas, si se ve en ellas una intención legislativa de optar por alguna tesis debatida al interior de la epistemología. Desde esta perspectiva, las consideraciones prácticas y morales tienen un rol complicado e interdependiente que jugar ${ }^{142}$.

A mayor abundamiento, el mismo STEIN señala que las reglas de exclusión son una forma de distribuir el riesgo de error, de segunda categoría. Estas se refieren al control respecto del peso epistémico de la prueba sobre la cual los jueces del juicio hacen su estimación de probabilidad de acaecimiento respecto de los hechos ${ }^{143}$. Para Ho, el empleo de las reglas de exclusión es una de las tres técnicas más importantes utilizadas en el common law de control de la deliberación ${ }^{144}$.

Desde esta perspectiva, el principio de inclusión de la prueba relevante, permitiéndose solo una exclusión excepcional en el caso de prueba manifiestamente impertinente, es un sistema de control a priori de la calidad de la prueba por el cual ha optado el legislador chileno. Y dicha elección también puede ser vista como una decisión política, extraepisté-

\footnotetext{
137 Así, también, Cordero (2006), p. 46. En un sentido similar en lo que refiere al Código Modelo para América Latina que contiene una referencia expresa a la exclusión de "pruebas manifiestamente inconducentes", véase, TARUFFo (2008) p. 39.

138 STEIN (2005) p. 138.

139 Ho (2008) p. 32.

140 STEIN (2013) p. 251.

141 DAMAŠKa (1995) p. 357.

142 Ho (2008) p. 37.

143 STEIN (2005) p. 134.

144 Ho (2008) p. 40.
} 
mica, porque se ha elegido un solo sistema de todos los disponibles. Desde esta perspectiva, la adopción del principio de inclusión de la prueba relevante puede ser vista como una solución justificada legislativamente a partir de la cautela de diversos intereses no exclusivamente epistémicos ${ }^{145}$.

En línea con lo anterior, considero que el criterio general de exclusión intrínseco está dado por la relevancia y/o pertinencia, siendo la exclusión de prueba de hechos notorios o públicos y de la prueba dilatoria regulaciones que responden más bien a justificaciones genuinamente extrínsecas pues, en todos estos casos, dichas hipótesis no son incompatibles con la relevancia de la prueba que se excluye. Más bien estas pruebas, en concreto, no son útiles para averiguar la verdad de lo sucedido, con independencia de su relevancia analizada ex ante y desde una perspectiva genérica.

La distribución del riesgo de error en fase de admisión también se concreta con una estrechez o poca entidad de las reglas de exclusión intrínsecas, con la finalidad de erradicar un proceso de averiguación sobre los hechos que, atendido el nivel de discusión de las cuestiones epistémicas y su poca seguridad, contenga riesgos de fallo inaceptables e intolerables por la exclusión de información relevante y/o útil. El legislador ha optado solo por un control de mínimos epistémicos en sede de fase intermedia. Es decir, en mi opinión, por todas las consideraciones anteriores es válida en sede de admisión probatoria la asunción de que "más prueba es mejor".

La cuestión aludida se realiza a partir de la facultad que asiste solo al poder legislativo $^{146}$ de concretar por vía legal la forma que adoptará el debido proceso, con clara alusión dentro de él al derecho a la prueba. Si estoy en lo correcto, entonces tiene mucho sentido que estas reglas, desde la mirada moral y/o política, solo sean concebidas como excepcionales y de interpretación estricta. Ello, además, porque forman parte de un sistema conjunto o unitario de distribución del riesgo de error en relación con la prueba en el proceso penal chileno. Y, como veíamos, cualquiera alteración injustificada puede generar un desbalance o distorsión que altera el sistema en su totalidad, generándose con ello un posible daño a los intervinientes.

El legislador, a partir de los enunciados legales descritos, ha zanjado políticamente que el tema del control epistémico lleva ínsito la perspectiva lógica -implícita a la valoración racional de la prueba- pero también que la cuestión epistémica se refiera a la constatación de mínimos, cuyo incumplimiento vuelva inútil el empleo de dicha prueba para averiguar la verdad y genere con ello un riesgo intolerable de injusticia. Y ese control de mínimos debe circunscribirse a la relevancia en su sentido probabilístico o material.

Por lo demás, también ello es coherente con el principio de economía procesal, la potencia normativa del derecho a la prueba y la titularidad de la decisión sobre los hechos por medio de una motivación que ha hecho al TJOP. El legislador también podría optar por excluir una específica prueba por razones epistémicas, como ocurre en el ámbito anglosajón con la exclusión del testimonio de oídas ${ }^{147}$, o la prueba sobre hechos públicos o

\footnotetext{
145 En este sentido, BuRGESS-JACKSON (1986) p. 464: "The law of relevance is, in short, multi-valued".

146 Así, Ferrer (2010) p. 11.

147 Véase, Ho (2008) pp. 231 ss.; TARufFo (2008) p. 43.
} 
notorios y la exclusión de la prueba dilatoria en nuestro sistema. Pero en todo caso, se debe tener claridad que ello solo puede ocurrir a partir de una regla específica que permita la exclusión, atendiendo la protección de otros valores, porque esa es la forma que se expresa la administración de la distribución del riesgo de error y, en definitiva, la prevalencia de otro interés por sobre el de la averiguación de la verdad. Así, no se debe descuidar que, por más que existan razones poderosas para el empleo de una regla de exclusión en atención al interés que intenta proteger, ello siempre se traduce en una limitación de la búsqueda de la $\operatorname{verdad}^{148}$. Y, como sostiene FERRER, el valor de la averiguación de la verdad no tiene estructuralmente la misma posición que los otros intereses en juego, porque ello es necesario para que el derecho funcione como mecanismo de motivación de la conducta de los ciudada$\operatorname{nos}^{149}$. Para mí, sin desconocer la opinión anterior, ello se fundamenta en que la búsqueda de la verdad de los hechos condiciona la justicia de la decisión sobre los hechos.

Desde esta perspectiva, el CPP chileno sería tributario del principio de inclusión de la prueba relevante, por lo que las exclusiones probatorias basadas en filtros epistémicos o extraepistémicos, además de expresamente consignadas, deben ser interpretadas estrictamente al haber optado el legislador solo por el control de mínimos epistémicos en sede de admisibilidad probatoria.

\section{CONCLUSIONES}

En este trabajo he intentado mostrar y justificar que el legislador chileno, en sede de admisión de prueba en el proceso penal chileno, en lo referente a la depuración epistémica, ha adoptado el principio de inclusión de la prueba relevante, cuya función inclusiva se desarrolla a través de control de una relación lógica de la información de la prueba con el thema probandum y una relación de probabilidad de la misma, de forma que esta pueda aportar aunque sea un mínimo dato para determinar la probabilidad de acaecimiento de algún enunciado fáctico de importancia para la decisión sobre los hechos del caso. Para ello, luego de despejar algunas cuestiones metodológicas, he intentado proporcionar diversas razones. Por ejemplo, epistémicas, al asumir que el legislador opta por la conveniencia de privilegiar la mayor entrada de información posible a juicio, porque con ello se aumenta la probabilidad de arribar a la verdad de la decisión. De otro lado, el diseño normativo-positivo contiene reglas de exclusiones más bien estrictas ("manifiesta impertinencia") y una regla de cierre que parece ratificar el principio de inclusión (art. 276 CPP inciso final). Por último, frente a la diversidad de problemáticas epistemológicas, el legislador ha decido asignar un riesgo de error a partir de estas reglas que solo habilite para controlar en sede de admisión un mínimo epistemológico de la prueba entre otras razones, también considerando el derecho a la prueba como parte integrante del debido proceso, principios de economía procesal y la titularidad de la decisión jurisdiccional de los hechos que corresponde al TJOP.

\footnotetext{
148 TARuffo (2010) p. 162.

149 Ferrer (2010) p. 13. En el mismo sentido, dándole primacía a la búsqueda de la verdad, BURGESS-JACKSON (1986) p. 479.
} 


\section{BIBLIOGRAFÍA CITADA}

Andrés IbÁÑEZ, Perfecto (1992): "Acerca de la motivación de los hechos en la sentencia penal", Doxa, No 12: pp. 257-299.

Bentham, Jeremy (1843): The work of Jeremy Bentham, Vol.VI (Edinburgh, London, Simpkin, Marshall \& Co).

Bentham, Jeremy (1825): A treatise of judicial evidence (London, Messrs, Baldwin, Cradock, and Joy, Paternoster-Row).

Bentham (2001): Tratado de las pruebas judiciales (Trad. Manuel Ossorio, Granada, Comares).

Binder, Alberto (1999): Introducción al Derecho procesal penal (Buenos Aires.Ad-hoc, 2a edición).

Bordalí Salamanca, Andrés (2016): Derecho jurisdiccional (Valdivia, Universidad Austral).

Burgess-JaCKSOn, Keith. (1986): "An epistemic approach to legal relevance”. St. Mary's Law Journal, No 18, Vol. 2: pp. 463-480.

Cafferata Nores, José (1998): La prueba en el proceso penal (Buenos Aires. Ediciones Depalma, $3^{a}$ edición).

Couture, Eduardo (2005): Fundamentos del Derecho procesal civil (Montevideo, Buenos Aires, B de F).

Cordero, Franco (2006): Procedura penal (Milano, Giuffrè, Ottava edizione).

Carocca Perez, Alex (2002): La defensa penal pública (Santiago, LexisNexis-Conosur).

ChahuÁn SARras, Sabas (2012): Manual del nuevo procedimiento penal (Santiago, Thomson Reuters, $7^{\text {a }}$ edición).

DAMAšKA, Mirjan (1995): "Free proof and its detractors", American Journal of Comparative Law, No 43, Vol. No 3: pp. 343-358.

DAMAŠKa, Mirjan (2015): El derecho probatorio a la deriva (trad. Joan Picó, Madrid, Barcelona, Buenos Aires, São Paulo, Marcial Pons).

Denbeaux, Mark y Risinger, D. Michael (2003): "Kumho Tire and Expert Reliability: How the Question You Ask Gives the Answer You Get", Seton Hall Law Reviewm, Vol. 34. Iss. 1: pp. 15-75.

DucE Julio, Mauricio (2010): "Admisibilidad de la prueba pericial en juicio orales: un modelo para armar en la jurisprudencia nacional”, en Accatino Scaglioti, Daniela (coord.), Formación y valoración de la prueba en el proceso penal (Santiago, LegalPublishing).

Duce Julio, Mauricio (2017): La prueba pericial (Buenos Aires, Ediciones Didot).

DWYeR, Déirdre (2008): The judicial assessment of expert evidence (Cambridge, Cambridge University Press).

Ferrer Beltrán, Jordi (2007): La valoración racional de la prueba (Madrid, Barcelona, Marcial Pons).

Ferrer Beltrán, Jordi (2010): "La prueba es libertad, pero no tanto: una teoría de la prueba cuasi-benthamiana”, en Accatino Scaglioti, Daniela (coord.), Formación y valoración de la prueba en el proceso penal (Santiago, LegalPublishing).

Gascón Abellán, Marina (2010): Los hechos en el derecho (Madrid, Barcelona, Buenos Aires, Marcial Pons, $3^{\text {a }}$ edición). 
Gascón Abellán, Marina (2013): "Prueba científica. Un mapa de retos" en VázQuez Carmen (ed.) Estándares de prueba y prueba cientifica (Madrid/Barcelona/Buenos Aires/Sao Paulo, Marcial Pons).

Göbel, Klaus (2013): Strafprozess (München, Verlag C.H. Beck, 8 Auflage).

HaAcK, Susan (2004): "Epistemology Legalized: Or, Truth, Justice, and the American Way", American Journal of Jurisprudence, Vol. 49: pp. 43-62.

Hand, Learned (1901): "Historical and Practical Considerations Regarding Expert Testimony", Harvard Law Review, No 15: pp. 40-58.

Hernández Basualto, Héctor (2010): "Pertinencia como garantía: prevención del prejuicio en el examen de admisibilidad de la prueba”, en Accatino Scaglioti, Daniela (coord.), Formación y valoración de la prueba en el proceso penal (Santiago, LegalPublishing).

Ho, Hock Lai (2008): A Philosophy of Evidence Law (Oxford, Oxford University Press).

Horvitz Lennon, María Inés y López Masle, Julián (2004): Derecho procesal penal chileno, Tomo II (Santiago, Editorial Jurídica de Chile).

IgARTÚa SALAVERria, Juan (2003): La motivación de las sentencias, imperativo constitucional (Madrid, Centro de Estudios Políticos y Constitucionales).

Igartúa Salaverria, Juan (2013): La "sucinta explicación" en el veridicto del jurado (Valencia, Tirant lo Blanch).

Ingram, Jefferson (2012): Criminal Evidence (Waltham, Elsevier, $11^{\text {th }}$ Edition).

Jauchen, Eduardo (2006): Tratado de la prueba en materia penal (Buenos Aires, RubinzalCulzoni).

JaCKSON, John (1996): "Analysing the New Evidence Scholarship: Towards a New Conception of the Law of Evidence", Oxford Journal of Legal Studies, Vol. 16, No 2 (Summer, 1996): pp. 309-328.

JaCKSOn, John y Summer, Sarah (2012): The Internationalizations of Criminal evidence (Cambridge, Cambridge University Press).

KIRKPATRICK, Laird C. (1992): "Scholarly and institutional challenges to the law of evidence: From Bentham to the ADR movement", Loyola of Los Angeles Law Review, Vol. 25, No 3: pp. 837-852.

KüHne, Hans-Heiner (2015): Strafprozessrecht (Heilderberg, C. F. Müller, 9 Ausflage).

Landsman, Stephan. (1990): "From Gilbert to Bentham: The reconceptualization of evidence theory", Wayne Law Review, Vol. 36, № 3: pp. 1149-1186.

Laudan, Larry (2013): Verdad, error y proceso penal (Trad. Carmen Vázquez y Edgar Aguilera, Madrid, Barcelona, Buenos Aires, Sao Paulo, Marcial Pons).

Maier, Julio (1996): Derecho procesal penal. Tomo III (Buenos Aires, Del Puerto, 2a edición).

Maturana Miquel, Cristián y Montero López, Raúl (2017): Derecho procesal penal. Tomo I (Santiago, Librotecnia, $3^{a}$ edición).

MaY, Richard (1999): Criminal evidence (London, Sweet \& Maxwell).

Montero Aroca, Juan (2005): La prueba en el proceso civil (Madrid, Thomson/Civitas, $4^{\mathrm{a}}$ edición).

Murphy, Peter (2010): "No free lunch, no free proof", Journal of International Criminal Justice, Vol. 8, No 2: pp. 539-574.

Nemeth, Charles (2001): Law \& Evidence (New Jersey, Prentice Hall). 
Peters, Karl (1985): Strafprozess (Heilderberg, C. F. Müller Juristischer Verlag, 4 Auflage). Redmayne, Mike (2002): "The relevance of bad character", The Cambridge Law Journal, Vol. 61, No 3 (Nov. 2002), pp. 684-714.

Roberts, Paul y Zuckerman, Adrian (2010): Criminal evidence (Oxford, Oxford University Press).

Roxin, Claus (2000) Derecho procesal penal (trad. Gabriela Córdoba y Daniel Pastor, Buenos Aires, Editorial del Puerto).

STEIN, Friedrich (1990): El conocimiento privado del juez (trad. Andrés de la Oliva, Madrid, Centro de Estudios Ramón Areces).

STEIN, Alex (2013): "Con la prueba libre", Revista de Derecho (Valdivia), Vol. XXVI, No 2: pp. 245-261.

Stein, Alex (2005): Foundations of Evidence Law (Oxford: Oxford University Press).

TARuffo, Michele (2008): La prueba (trad. Laura Manríquez y Jordi Ferrer, Madrid, Barcelona, Buenos Aires, Marcial Pons).

TARuffo, Michele (2010): Simplemente la verdad (trad. Daniela Accatino, Madrid, Barcelona, Buenos Aires, Marcial Pons).

TARuffo, Michele (2011): La motivación de la sentencia civil (trad. Lorenzo Córdova, Madrid, Editorial Trotta).

Thayer, James (1898): A Preliminary Treatise on Evidence at the common law (Boston. Little, Brown and Company).

TwInInG, William (1985): Theories of evidence: Bentham and Wigmore (London, Weidenfeld $\&$ Nicolson).

Twining, William (1997): "Freedom of Proof and the Reform of Criminal Evidence", Israel Law Review, No 31, Issues 1-3: pp. 439-463.

Twining, William (2006): Rethinking evidence (Cambridge, Cambridge University Press, $2^{\circ}$ edition).

Ubertis, Giulio (2017): Elementos de Epistemología del proceso judicial (Trad. Perfecto Andrés, Madrid, Editorial Trotta).

Valenzuela Saldias, Jonatan (2017): Hechos, pena y proceso (Santiago, Rubicón).

VÁzQuez Rojas, Carmen (2015): De la prueba científica a la prueba pericial (Madrid/Barcelona/Buenos Aires/Sao Paulo, Marcial Pons).

VÁzQuez Sotelo, José Luis (1984): Presunción de inocencia del imputado e intima convicción del Tribunal (Barcelona, Editorial Bosch).

Vera SÁnchez, Juan Sebastián (2017): "Naturaleza jurídica de la Fase Intermedia del proceso penal chileno. Un breve estudio a partir de elementos comparados", Revista de Derecho de la Pontificia Universidad Católica de Valparaíso, No 49: pp. 141-184.

Wigmore, John Henry (1937): The Science of judicial proof, as given by logic, psychology, and general experience, and illustrated in judicial trials (Boston, Little, Brown, $3^{\circ} \mathrm{ed}$.).

\section{JURISPRUDENCIA CITADA}

Ministerio Público con Rigoberto Antonio Villablanca Ibáñez (2005): Corte Suprema, 14 de septiembre, Rol No 3666-2005 (Recurso de Nulidad). 
Andrea Cifuentes Domínguez con Belén Andrades Riquelme y otros (2016): Corte Suprema, 26 de enero, Rol No 37635-2015 (Recurso de Nulidad)

REQUERIMIENTO DE INAPLICABILIDAD POR INCONSTITUCIONALIDAD PRESENTADO POR ROSSANA Donoso Mura respecto del inciso tercero del artículo 196 de la ley No 18.290, EN EL PROCESO PENAL RUC 1510041999-5, RIT 3759-2015 DEL Juzgado de Garantía de Los Andes, en actual conocimiento de la Corte de Apelaciones de Valparaíso, por RECURSO de APELACIÓN, BAJO El Rol IC 1740-2016 (2017): Tribunal Constitucional, 5 de octubre de 2017, Rol No 3251-2016.

Requerimiento de inAPlicabilidad POR inCONSTITUCiOnalidad PRESENTAdo POR Pablo Duvingelo Alfaro respecto de los artículos 387, inciso primero, del Código Procesal Penal y 158 del Código de Procedimiento Civil, en los autos sobre recurso de Queja, De que conoce la Corte Suprema, bajo el Rol No 3105-2015 (2015): Tribunal Constitucional, 26 de febrero de 2015, Rol No 2802-15.

REQUERIMIENTO DE INAPLICABILIDAD POR INCONSTITUCIONALIDAD PRESENTADO POR LEONARDO Rodríguez Sepúlveda respecto de las partes que indica del artículo 277 del Código Procesal Penal, en el marco del proceso penal Rit No 2171-2010 del Juzgado de Garantía de Concepción, en actual conocimiento del la Corte de Apelaciones de Concepción, por recurso de hecho en Rol No 28-2014 (2014): Tribunal Constitucional, 30 de diciembre de 2014, Rol No 2628-2014.

\section{NORMAS CITADAS}

Chile, Constitución Política de la República (11/8/1980).

Chile, Código procesal penal (12/10/2000).

España: Ley 1/2000, "Ley de Enjuiciamiento civil española" (07/0172000).

Estados Unidos, Federal Rules of Evidence (2/1/1975). 